\title{
Overview of Epidemiological and Etiological Amputation in Kisangani Democratic Republic of Congo (DRC)
}

\author{
Lehumadi Talona ${ }^{1}$, Azabali Maoneo', Toha Kuyigwa², Basandja Ossinga ${ }^{3}$, \\ Lokosa Lomodo ${ }^{4}$, Ona L. Ahuka ${ }^{*}$ \\ ${ }^{1}$ Department of Surgery, Medical School, University of Kisangani, Kisangani, Democratic Republic of the Congo \\ ${ }^{2}$ Department of Surgery, Medical School, Catholic University of Bukavu, Bukavu, Democratic Republic of the \\ Congo \\ ${ }^{3}$ Department of Internal Medicine, Medical School, University of Kisangani, Kisangani, Democratic Republic of \\ the Congo \\ ${ }^{4}$ University Clinics of Kisangani, Kisangani, Democratic Republic of the Congo \\ Email: "ahukaona@gmail.com
}

Received 5 April 2016; accepted 24 May 2016; published 27 May 2016

Copyright (C) 2016 by authors and Scientific Research Publishing Inc.

This work is licensed under the Creative Commons Attribution International License (CC BY).

http://creativecommons.org/licenses/by/4.0/

(c) (7) Open Access

\begin{abstract}
Background: Amputations and disarticulation of the limbs are becoming a public health problem. Goal: To describe the epidemiological and etiological aspects of limb amputation in Kisangani. Methods: A retrospective study of three health facilities in the city of Kisangani: Kisangani Clinical University, General Hospital Makiso-Kisangani Reference and Kabondo Reference General Hospital from $1^{\text {st }}$ January 2005 to $31^{\text {st }}$ December 2014 counted 62 cases of amputation. Results: The prevalence of $14.69 \%$ of all interventions of limbs. The age group of $57-75$ years is the most concerned and the male/female sex ratio is $2.9 / 1$. The unemployed are most affected $51.6 \%$. The lower limb is concerned in $88.7 \%$, including $30.6 \%$ in the lower leg and the right side is reached in $56.5 \%$ of cases. Diabetic gangrene $(30.1 \%)$ is criminalized followed by traumatism $(27.4 \%)$. The mortality rate is $\mathbf{1 7 . 8 \%}$. Conclusion: The amputation of limbs is a situation encountered in Kisangani. The adult male is most affected. Diabetic gangrene and open fractures are the most encountered causes. Mortality is high. The early management of diabetics and open fractures is a mandatory.
\end{abstract}

\section{Keywords}

Amputation, Diabetic Gangrene, Open Fractures, Kisangani

\footnotetext{
${ }^{*}$ Corresponding author.
}

How to cite this paper: Talona, L., Maoneo, A., Kuyigwa, T., Ossinga, B., Lomodo, L. and Ahuka, O.L. (2016) Overview of Epidemiological and Etiological Amputation in Kisangani Democratic Republic of Congo (DRC). Open Journal of Epidemiology, 6, 154-159. http://dx.doi.org/10.4236/ojepi.2016.62016 


\section{Introduction}

The removal of part or whole limb, amputation, seriously hampers the achievement of the Millennium Development Goals by reducing productivity [1] [2]. It is a mutilating surgery that alters body image and leads to severe functional deficits. When made at a joint, it is called disarticulation. Any limb amputation painfully affects the patient in his daily activities, his job, his leisure [3] and a handicap that will effect on many levels and so intricate functional abilities, his social and professional life and psychology. Therefore, its realization is a part of a therapeutic approach in which the risk-benefit ratio should be carefully evaluated [4]. The limb amputations still represent today a serious public health problem, affecting both human and substantial financial; thus, we are more and more helping to the development of limb salvage concept in the north countries [5]. In low income countries, amputations are more traumatic. And those affected are not necessarily the older people but young assets [6]. In the Worldwide, the upper limb amputations are rare, affecting more men, the dominant limb is achieved, traumatic and tumor causes are the majority [7]. Socio-professional reintegration is not yet well established in most low-income countries like the Democratic Republic of Congo (DRC), where only few studies have focused on this subject, including one conducted in January 1996 by Ahuka and Lusi [8] and a recent one by Valimungighe MM et al. en 2015 [9]. The objective of this study is to describe the epidemiological and etiological aspects of limb amputation in Kisangani.

\section{Methodology}

\subsection{Environment of Study}

Kisangani, formerly Stanleyville is the capital of Orientale Province in the DRC. It is the third largest urbanized city in the country and the largest of the cities that lie in the tropical woodlands of the Congo. It is located at 1300 miles from the mouth of the Congo River. In 1999, the city was the site of the first open fighting between Ugandan and Rwandan forces in the second Congo war, when nearly 3000 people died in the cross fire. Despite being adjacent to the equator, the city has a tropical monsoon climate due to the fact that its driest month (January) sees on average below $60 \mathrm{~mm}$ of rain. Kisangani experiences an average relative humidity of 86\%. It's the most populous city of the Northern provinces in the RDC, with an estimated 2008 population of 1,200,000 (up from 406,249 thousand in 1993).

\subsection{Type of Study}

This study is descriptive retrospective over a period of ten years; it was taken to the University Hospital of Kisangani and Hospitals General Referral (HGR) Kabondo and Makiso-Kisangani.

\subsection{Study Population}

This study involved all patients who underwent amputation or disarticulation from $1^{\text {st }}$ January 2005 to $31^{\text {st }}$ December 2014 (10 years). Included are hospitalized and operated patients having a complete medical file. All patients with incomplete data were excluded from this study. The age, sex, occupation, the amputated limb, the type of amputation, the site or amputation level, the affected side, the etiology, and the patient output modality were the variables of the study. The level of amputation was determined by the progression of the gangrene or the site of open fractures.

Any amputation located above the wrist and the ankle is considered major when she is labeled a minor when she performs below these levels.

\subsection{Statistical Analysis}

Data were collected using a standardized form from the patient records, the register of the operating room and the register of operating protocols. The percentage calculation allowed to describe the variables categories in various tables, the normal quantitative variables are described as mean and standard deviation. The Excel spreadsheet has facilitated data entry, which was analyzed using SPSS 20 software.

\section{Results}

\subsection{Main Features}

In 422 patients who underwent surgery Membership CUKIS and HGR Makiso-Kisangani and Kabondo during 
our study period, 62 of them underwent amputation of limbs, a prevalence of $14.69 \%$ of cases.

\subsection{Socio Demographic Amputees (Table 1)}

From Table 1 we notice that people ranged on group age between 57 - 75 years are most affected by the amputation of limbs with $30.7 \%$, masculine predominance in $74.2 \%$ sex-ratio male/female being $2.9 / 1$. Among all professional corporations, unemployed represent $51.6 \%$

\subsection{Characteristics of Amputees (Table 2)}

From Table 2, the vascular etiology (46.8\%) is the most criminalized, diabetes mellitus alone represents $30.7 \%$. The lower limb is most affected (88.7\%) while the right side was more concerned with 56.5\%. The major amputation is most common with 79\%, including 32.2\% in the leg side. It emerges from Table 3 that 51 (82.2\%) amputees were cured whereas 11 (17.8\%) died.

\section{Discussion}

The goal of this study was to describe the epidemiological and etiological aspects of limb amputation in Kisangani. There is a limitation of this study due on the limited number of hospitals where we collected data in a big town with over a million people. Nevertheless, we can discuss.

Throughout the explained by the study period from $1^{\text {st }}$ January 2005 to $31^{\text {st }}$ December 2014, 62 patients underwent a limb amputation, a total of 422 interventions concerning limbs, a prevalence of $14.69 \%$. This frequency is comparable to that found by Kanté et al. in Bamako, Mali, which is 31.25\% [10].

In our study, subjects whose age group was between 57 - 75 years were most affected with $30.7 \%$ close to that of Diakité [11] who recorded 33.3\% of lower limb amputees in a range 55 - 64 year old. This high incidence of amputations in old age could berelating to the prevalence of diabetic arterial disease.

Regarding gender, male patients had more limb amputation than those of the female, or $74.2 \%$ against $25.8 \%$ with a sex ratio of 2.9/1. These results match those of Ahuka and Lusi [8] at Nyakunde DRC (formerly Zaire) in 1996, who found $71.53 \%$ for males against $28.47 \%$ for females, with a sex ratio of $2.5 / 1$. This male prediction was reported by other authors [12]. We estimate that the male predominance can be explained not only by the fact that it is more exposed to road traffic accidents (RTA), but above all, the man is more accepting amputation than a woman, this latter favoring aesthetic considerations.

Table 1. Sociodemographic characteristics of amputees.

\begin{tabular}{|c|c|c|}
\hline Characteristics & Frequency (\%) & (\%) \\
\hline \multicolumn{3}{|l|}{ Age group (years) } \\
\hline$<18$ & 10 & 16.1 \\
\hline $19-37$ & 16 & 25.8 \\
\hline $38-56$ & 14 & 22.6 \\
\hline $57-75$ & 19 & 30.7 \\
\hline $76-94$ & 3 & 4.8 \\
\hline \multicolumn{3}{|l|}{ Sex } \\
\hline Male & 46 & 74.2 \\
\hline Female & 16 & 25.8 \\
\hline \multicolumn{3}{|l|}{ Profession } \\
\hline Unemployed & 32 & 51.6 \\
\hline Household & 9 & 14.5 \\
\hline Artisan & 6 & 9.7 \\
\hline Official & 6 & 9.7 \\
\hline Traders & 5 & 8.1 \\
\hline Pupils and students & 4 & 6.4 \\
\hline
\end{tabular}


Table 2. Amputations characteristics and etiologies.

\begin{tabular}{|c|c|c|}
\hline Amputed characteristics & Frequency & $\%$ \\
\hline \multicolumn{3}{|l|}{ Etiology } \\
\hline \multicolumn{3}{|l|}{ - Vascular } \\
\hline Diabetic gangrene & 19 & 30.7 \\
\hline Nondiabetic arteriopathies & 10 & 16.1 \\
\hline \multicolumn{3}{|l|}{ - Traumatic } \\
\hline Open fractures (crushing) & 16 & 25.8 \\
\hline Dislocation open & 1 & 1.6 \\
\hline - Tumor & 10 & 16.1 \\
\hline - Infectious & 4 & 6.5 \\
\hline - Congenital malformations & 2 & 3.2 \\
\hline Amputations characteristics & Frequency & $\%$ \\
\hline \multicolumn{3}{|l|}{ Side limb } \\
\hline Right & 35 & 56.5 \\
\hline Left & 26 & 41.9 \\
\hline Mixed & 1 & 1.6 \\
\hline \multicolumn{3}{|l|}{ Amputed limb } \\
\hline Lower limb & 55 & 88.7 \\
\hline Upper limb & 7 & 11.3 \\
\hline \multicolumn{3}{|l|}{ Amputation type } \\
\hline - Major Amputation & 49 & 79 \\
\hline Leg & 20 & \\
\hline Thigh & 18 & \\
\hline Knee disarticulation & 9 & \\
\hline Ankle disarticulation & 1 & \\
\hline Forearm & 1 & \\
\hline - Minor amputation & 23 & 21 \\
\hline
\end{tabular}

Table 3. Output modality.

\begin{tabular}{cc}
\hline Output modality & Frequency (\%) \\
\hline Healing & $51(82.2)$ \\
Death & $11(17.8)$ \\
\hline
\end{tabular}

It emerges from the analysis of our results as the unemployed represent the majority of cases of amputation, or 51.6\%. Ebskov, Schroder TV, Holstein [13] in Britain in 1994 had reached similar results (42\%). We believe this category of the population, lack of adequate financial resources, consult later when the disease has already evolved and often in an irreversible stage, indicating the amputation. On the other hand, accidents of traffic occurring frequently in unemployed subjects [14] [15] can explain this amputation rate in this occupational category.

The analysis of our data shows that diabetic gangrene was more frequent (30.7\%), followed by $25.8 \%$ with open fractures and malignant tumors (16.1\%). In France, Mallory in 2014 [16] and Quesnay in 2013 [17], had noted respectively $85 \%$ - 93\% of vascular causes, followed by $5 \%$ to $16 \%$ of traumatic causes. About lower limb amputations, the opinions of the authors differ. Ogundele OJ et al. in Nigeria [13] instead, as us, has foreground the diabetes mellitus followed by trauma. Ajibade A et al., also in Nigeria, all causes of amputation combined, recorded different distributions of us; trauma and subsequent gangrene in traditional medicine are respectively 
42.4\% and 31.8\% [18]. It must be stressed the importance of diabetes with 6 million new patients each year and is responsible for more than 4 million deaths annually, 1 million amputations (85\% of the total number of amputations) and multiple complications invalidate [19].

The results of this work show right side is predominant with $56 \%$ against $44 \%$ for the left side. Souna [3] found the same trend with $50.8 \%$ the right side to against 49.2 to the left side.

The lower limbs are more concerned with amputations or $88.7 \%$ against $11.3 \%$ of the upper limbs in our series. In this regard, our results are similar to those of other authors. Sunna et al. [3] in Mali found $74.1 \%$ for the lower limbs and Ahuka and Lusi [8] in DRC had found 66\%. Ogundele OJ et al. Nigeria [12] reported a rate of $75.8 \%$ and $24.2 \%$ respectively for the lower limbs and upper limbs. We believe that being a diabetic foot disease develops gradually with a changing saw tooth, and also an inadequate initial support, lets lesions evolve to irreversible complications [9] [10]. In addition, the lower limbs are conventionally known as the predilection of diabetic arterial disease [4] [9]. Also, the legs are exposed to road traffic accidents because they are at the height of bumpers and tire's rolling machines [14].

The analysis of our data shows that major amputation is the most common with $79 \%$. Ahuka and Lusi [8] in 1996 Nyakunde had found 79\% of major amputation against 21\% of minor amputation. Richardson C et al. on the other hand found that minor amputations predominate, with 43\%, mainly for the upper limbs [20].

In our series, the amputation at the leg was more frequent with $52.7 \%$ of cases. Our transtibial rate amputation is similar to Mezghani et al. [6] and 47\%, and Quesnel [17].

It appears from our study that $17.8 \%$ died. These results are higher than those found by Bisseriex et al. who obtained a death rate of $12.5 \%$ [21]. Our results could be explained by the changed nature of the initial lesions. We must recognize here regarding diabetes, weak management capabilities associated with a prohibitive cost of treatment resulting frequencies very high complications [22] and emphasize that chronic diseases, including diabetes, are a threat serious due to their severity and prevalence [23].

\section{Conclusion}

The amputation is a situation encountered in Kisangani. The adult male is most affected. Diabetic gangrene and open fractures are the most encountered causes. Mortality is high and due to the precariousness of the economic fabric as shown by the high rate of unemployment. The early management of diabetes can help lower amputations in our midst. Only a real political will of governments and medical and many other actors of the public and private sectors will be achieved.

\section{References}

[1] Aouiha, M. and Kaushik, R.N. (2010) Novo Diabetes: The Silent Pandemic and Its Impact in Sub-Africa Forum. Diabetes Leadership Forum, Johannesburg, 30 September-1 October 2010, pg ii 4.

[2] MDGs (2015) (Millennium Development). Role of the World Bank in 2015.

[3] Sunna, B., Mamoudou, A. Guigma, A. and Nouhou, H. (2009) The Cause of limb Amputations Study Retrospective and Prospective of 87 Cases of Limb Amputations. Mali Médical, XXIV, 12-16.

[4] Maurer, P. (2014) Defective Painful Stump. Medico-Surgical Encyclopaedia, Surgical Technique, Orthopedics, 44120.

[5] Van Velzen, J.M., van Bennekom, C.A., Polomski, W., Slootman, J.R., van der Woude, L.H. and Houdijk, H. (2006) Physical Ability and Walking Capacity After-Lower Limb Amputation: A Systematic Review. Clinical Rehabilitation, 20, 999-1016. http://dx.doi.org/10.1177/0269215506070700

[6] Mezghani Masmoudi, M., Guermazi, M., Feki, H., Ennaouai, A., Dammak, J. and Elleuch, M.H. (2004) Factors Related to Functional and Professional Future of Lower-Limb Amputees Splicers. Annals of Rehabilitation and Physical Medicine, 47, 114-118.

[7] Oberlin, P., Mouquet, M.-C. and Got, I. (2006) Foot Lesions in Adults with Diabetes. What Treatment Options in the Hospital? Studies and Results, 473, 1-8.

[8] Ahuka, O.L. and Lusi, M.K. (1995) Epidemiological and Etiological Study of Rural Amputations Northeast Zaire. East and Central African Journal of Surgery, 1, 33-35.

[9] Valimungighe, M.M., Bunduki, G.K., Kamabu, K.L. and Uwonda, A.S. (2015) Risk Factors of Diabetic Patients in Amputation at Butembo, Democratic Republic of Congo. International Journal of Advanced Research Current Research, 4, 353-356.

[10] Kante, L., Togo, A., Diakité, I., et al. (2012) Epidemiological and Therapeutic Study of Consecutive Amputations for 
Diabetes Complications. Mali Medical, IV, 11-13.

[11] Diakite, S.K. (2004) Diabetic foot in Orthopaedic Surgery and Traumatology Service of C.H.U./Donka. 7th Congress SICOT/SIROT; Gothenburg, 31 August-3 September 2010, 25-26.

[12] Ogundele, O.J., Ifesanya, A.I., Oyewole, A.O. and Adegbehingbe, O.O. (2015) Major Limb Amputations at a Teaching Hospital in the Sub-Saharan Africa: Any Change in Trend? East and Central African Journal of Surgery, 20, 140-145.

[13] Ebskov, L.B., Schroder, T.V. and Holstein, P.E. (1994) Epidemiology of Leg Amputation; the Impact of Vascular Surgery. British Journal of Surgery, 81, 1600-1603. http://dx.doi.org/10.1002/bjs.1800811111

[14] Kuyigwa, T.G., Ahuka, O.L., Kabakuli, N.A., Kabinda, J.M. and Uwonda, A.B. (2015) Fracture of Limbs Bones in a Town in Post Conflict (Case of Bukavu Town). Open Journal of Epidemiology, 5, 244-250.

[15] Naddumba, E.K. (2008) Musculoskeletal Trauma Services in Uganda. Clinical Orthopedics and Related Research, 466, 2317-2322. http://dx.doi.org/10.1007/s11999-008-0369-2

[16] Mallory J. (2014) Prosthetic Apparatus for the Amputee Patient of Vascular Etiology. Analysis of Interest and Short-Term Constraints from Two Clinical Cases Masso Physiotherapy. Pays de la Loire in 2014.

[17] Quesnel, A. (2013) Functional Become a Cohort of Patients with Lower Limb Amputees. Thesis for the Doctorate in Medicine, U.F.R of Medicine-Pharmacy, Rouen.

[18] Ajibade, A., Akinniyi, O.T. and Okoye, C.S. (2013) Indications and Complications of Major Limb Amputations in Kano, Nigeria. Ghana Medical Journal, 47, 185-188.

[19] International Diabetes Federation (2011) Diabetes Atlas. 5th Edition, Brussels.

[20] Richardson, C., Glenn, S., Nurmikko, T. and Horgan, M. (2006) Impact of Phantom Phenomena Including Phantom Limb Pain 6 Months After-Major Lower Limb Amputation in Patients with Peripheral Vascular Disease. Clinical Journal of Pain, 22, 353-358. http://dx.doi.org/10.1097/01.ajp.0000177793.01415.bd

[21] Bisseriex, P.M., Rogez, D., Thomas, M., et al. (2011) Amputation in Low Income Countries: Particularities in Epidmiological Features and Management Practices. Médecine Tropicale, 71, 565-571.

[22] Besançon, S. (2013) Africa and Diabetes. The End of a Paradox. Diabetes \& Obesity, 8, 35-40.

[23] World Economic Forum (2015) Global Risks 2010. http://www.weforum.org/pdf/globalrisk/globalrisks2010.pdf 